\title{
Editorial
}

\section{CHOLEDOCHOCHAL CYST}

Choledochal Cyst is an uncommon disease but not rare. The actual incidence is not known.

In 1852, Douglas published the first clinical description of a patient of dilatation of common bile duct, which he suggested was probably congenital in origin ${ }^{1}$. Other than occasional reports of Choledochal Cyst that were published after that, it was not until 1959 that AlonsoLej and colleagues published the first series of patients with Choledochal Cysts, reporting 2 of their own cases and reviewing 94 others previously published in the literature $^{2}$. This paper was the first to describe a classification including the three common form of Choledochal Cyst for which different approaches to treatment were suggested.

Type I, II \& III forms of Choledochal Cyst were originally described by Alonso- Lej and colleagues. Todani and associates and others have further classified the anomaly into five main types and additional subtypes, based on analysis of cholangiogram ${ }^{3,4}$. The common varieties are - Type I, II , III, IV \& V. Sometimes type III \& IV co-exist. 90 to 95 percent of Choledochal Cysts are type I variety, being either fusiform or saccular, with the fusiform type being more common ${ }^{5}$.

Histologic section of extrahepatic Choledochal Cyst reveals thick wall structure of dense connective tissue interlaces with strands of smooth muscle. Some degree of inflammatory reaction is noted. It is minimal in infants \& gradually more marked as patient get older.

The histologic appearance of other forms of Choledochal cyst is similar except choledochocele. In these cyst, the lining is most commonly duodenal mucosa and only occasionally resembles lining of the bile duct.

The findings on liver biopsy also vary with the age of the patient. In new born histologic appearance is usually normal or mild bile duct proliferation consistent with chronic biliary obstruction.In older patients mild periportal fibrosis is noted. Ramirez and associates ${ }^{6}$ and others, have reported the coexistence of congenital hepatic fibrosis with choledochal cyst.Carcinoma in the wall of a choledochal cyst has been rarely been reported in childhood and primarily a problem in adults. In 1984, Todani and co-workers, in an analysis of retrograde Cholangiopancreatography (ERCP) suggested that the most patients had an anomalous arrangement of the pancreaticobiliary ductal system in which the pancreatic duct entered the common bile duct in a proximal location,well outside the circular muscle of the ampulla of Vater,which would permit reflux of pancreatic enzymes containing trypsin upward into common bile duct during fetal development resulting damage of ductal wall and subsequent dilatation. ${ }^{7}$ This 'common channel ' theory related to the etiology of choledochal cyst was originally was suggested by Babbitt in $1969 .{ }^{8}$ Ito,Miyano, Spitz and others have suggested that obstruction of the level of duodenum is an additive factor in this Process, which tends to produce saccular dilatation of distal common bile duct. $9,10,11$ Any degree of distal obstruction would be expected to increase the opportunity for reflux of Pancreatic enzymes into the proximal biliary tree.

Patients with choledochal cysts usually present in one of two ways, which has led to them being classified as infantile or adult in nature. In infantile form patient ranging from 1 to 3 months of age present with obstructive jaundice, acholic stools and hepatomegaly with a clinical picture different from biliary atresia. ${ }^{12}$ In adult form of choledochal cyst clinical manisfestation donot generally become evident until after the patient is $2 \mathrm{yrs}$ of age. The classic triad of abdominal pain, a palpable mass and jaundice. 
Laboratory studies are not capable of either making or confirming the diagnosis of choledochal cyst but they indicate the clinical condition of the patient. Jaundice is the most presenting feature, so conjugated hyperbilirubinemia, increase serum alkaline phosphatase level and other serum markers of obstructive jaundice. Ultrasonography of hepatobiliary system is one of tool of diagnosis. If it is suspected choledochal cysts, DISIDA scintigraphy can confirm the diagnosis. ERCP provided the information of the frequency of pancreaticobiliary ductal malunion. But ERCP replaced by MRCP, because it is non invasive.

In follow-up period abdominal ultrasonogram,DISIDA scanning \& MRCP are helpful.

A variety of surgical management has been used through the years for choledochal cysts. In past, many patients were quite ill at the time they presented, so limited procedure such as aspirations, marsupialization and extended drainage were done.

Various options available for the operative management of choledochal cyst, cyst excision with Roux-en-Y hepaticojejunostomy is preferred. Todani and coworkers have preferred to use hepaticoduodenostomy after cyst excision. ${ }^{13}$ Regarding hepaticoduodenostomy cases long term follow up revealed the complications of chronic recurrent cholangitis due to reflux into biliary tree from the duodenum, resulting chronic inflammation and anastomotic stenosis. This led to insidious development of of severe biliary cirrhosis and portal hypertension. Cirrhosis did not become evident until more than 5 years after hepaticoduodenostomy. Gonzalez and associates ${ }^{14}$ have proposed using a $30 \mathrm{~cm}$ isolated conduit of proximal jejunum interposed between the confluence of hepatic duct and second portion of duodenum. Raffenperger ${ }^{15}$ has promoted the use of a valve jejunal interposition hepaticoduodenostomy.

Follow up studies indicate that Roux-en-Y hepaticojejunostomy is the preferred procedure. For the older patients who had recurrent bouts of cholangitis and pericystic inflammation and adherence to vascular structures, the technique originally reported by Lilly is useful ${ }^{16,17}$. Cysto-duodenostomy and cystojejunostomy are totally discarded due to higher incidence of malignancy.
Post operative follow up should be every 3 months for first year and then annually thereafter in asymptomatic patients. Liver function test, serum amylase, USG of liver and pancrease to be done. USG is helpful of Rouxen-Y ductal anastomosis because occasionally patient will develop late anastomotic strictures or stone.

Hay and co-workers ${ }^{18}$, Liu and colleagues ${ }^{19}$ have reported and discussed the role of laparoscopic techniques in the management of patient, with jaundice and choledochal cyst. It remains to be seen whether minimally invasive techniques will be applicable to be broad range of anomalies encountered in the management of patients with choledochal cyst malformation. At present, standard open procedures are preferred. robotic surgery, which provide an additional dimension minimally invasive surgery may be useful.

Saing and co-workers reported long term results in their long series of patient followed for over 20 years. Anastomotic stricture, cholangitis and intrahepatic stone formation are common complications. Risk of cancer was marked diminished by cyst excision.

\section{Prof. Md. Mahbub-ul-Alam \\ MBBS, FCPS(S), FICS \\ Professor \& Head, Department of Pediatric Surgery \\ Dhaka Medical College \& Hospital, Dhaka}

\section{References}

1. Douglas $\mathrm{AH}$ : Case of dilation of common bile duct. Monthly J Med Sci (Lond) 1852; 14:97

2. Alonso-Lej F.Rever WB,Pessagno DJ : Congenital choledochal cyst, with a report 2 , and an analysis of 94 cases.Surgical Gynecol Obstet Int Abstr Surg 1959;108:1-30

3. Todani T,Watanabe $Y$, Namsue M.et al : congenital bile duct cyst: classification, operative procedures and review of 97 cases including cancer arising from choledochal cyst. Am J surg 1977; 134:263-269

4. Todani T, Watenabe $Y$, Toki A et al. Co-existing biliary anomalies and anatomical variants in choledochal cyst. Br. J Surg 1998;85:760-763

5. O'Neill JA, Templeton JM, Schnowter L, et al: Recent experience choledochal cyst. Ann Surg 1987; 205: 533-540 
6. Ramirez MJ,Nieto J, Valencia P: Fibrosis hepatica congenital associada a quiste de coledoco. Bol Med Hosp. Intent Mex. 1989;46:803-807

7. Todani T, Watanabe Y, Fujii T et al: Anomalous arrangement of the pancreatico-biliary ductal system in patient with a choledochal cyst. Am J Surg 1984;147:672-676

8. Babbitt DP: Congenital choledochal cyst: New etiological concept based on anomalous relationships of common bile duct and pancreatic bulb. Ann radiol 1969;12:231-240

9. $\mathrm{Hu} \mathrm{T}$, Ando $\mathrm{H}$, Nagaya $\mathrm{M}$ et al: Congenital dilatation of common bile duct in children-the etiologic significance of the narrow segment distal to dilated common bile duct. Z Kindochir 1984; 39:40-45

10. Miyano T, Sugwric, Sudak $\mathrm{K}$ et al : Anomalous pancreatico choledochal ductal junction syndrome: A proposal of a new classification. $\mathrm{J}$ Jpr Soc Pedatr Surg 1985;21:75-81

11. Spitz J: Choledochal Cyst Surg Gynecol Obstet 1978;146:444-452
12. Davenport M, Betalli $\mathrm{P}$, D'Antiga et al: The spectrum of surgical jaundice in infancy. J pediatr Surg 2003;38:1471-1479

13. Todani T, Watanabe Y, Mizuguchi T et al Hepaticoduodenostomy at the hepatic hillum after excision of choledochal cyst. Am J Surg 1981;142:582587

14. Gonzalez EM, Garcia IG, Pascual H et al: Choledochal cyst resection and reconstruction by hepatico-jejuno-duodenal diversion. World J Surg 1989;13:232-237

15. Raffensperger (ed) : choledochal cyst. In Swenson's pediatric surgery. NY Appletoncentury-crotts 1980 pp. 614-619

16. Lilly JR: The surgical treatment of choledochal cyst. Surg Gynecol Obstet 1979;149:36-42

17. Lilly JR: Total excision of choledochal cyst. Surg Gynecol Obstet 1978;146:254-258

18. Hay SA, Soliman HE, Sharif HM et al: Neonatal jaundice: The role of laparoscopy. J Pediatr Surg 2000;35:1706-1709

19. Liu DC, Rodriguez JA, Merick F, Geiger JO: Laparoscopic excision of a rare type II choledochal cyst: Case report and review of literature. J Pediatr Surg 2000; 35: 1117-1119. 